\title{
Working and Training Conditions of Gynecology Residents in North Rhine-Westfalia, Germany
}

\author{
Arbeitszufriedenheit gynäkologischer Weiterbildungsassistenten \\ in Nordrhein-Westfalen, Deutschland
}

Authors

Affiliations
D. Fehr ${ }^{1}$, D. Rein ${ }^{2}$, T. Fehm ${ }^{1}$, M. Fleisch

${ }^{1}$ Frauenklinik, Univ.-Klinikum Düsseldorf, Düsseldorf, Germany

${ }^{2}$ Klinik für Gynäkologie und Geburtshilfe, St. Elisabeth-Krankenhaus Köln-Hohenlind, Köln

\section{Key words}

working conditions

- gynecology

- satisfaction

training

questionnaire

\section{Schlüsselwörter}

- Arbeitsbedingungen

- Gynäkologie

- Zufriedenheit

- Weiterbildung

- Umfrage

\section{Deutschsprachige} Zusatzinformationen online abrufbar unter: www.thieme-connect.de/ ejournals/toc/gebfra

\section{received 1.9.2013 \\ revised 10.11.2013 \\ accepted 24.11.2013}

\section{Bibliography}

DOI http://dx.doi.org/

10.1055/s-0033-1360221

Geburtsh Frauenheilk 2014; 74:

161-166 @ Georg Thieme

Verlag KG Stuttgart · New York ISSN 0016-5751

\section{Correspondence}

Dr. Daniel Fehr

Univ.-Klinikum Düsseldorf

Frauenklinik

Moorenstraße 5

40225 Düsseldorf

fehr@unikid.de

\section{Abstract}

\section{$\nabla$}

Introduction: In 2002, gynecology residents in North Rhine-Westfalia (NRW) were asked how satisfied they were with their working and training conditions. A new extended survey of gynecology residents aimed to evaluate whether changes to specialist training regulations had affected residents' levels of job satisfaction and to identify areas where training conditions still urgently required improvement.

Material and Methods: A total of 1223 questionnaires with 52 questions were sent to the 159 gynecology clinics in NRW. Responses could be dichotomous, multi-level or quantitative. The results were analyzed with regard to age, gender, family status and type of clinic and were additionally compared with the results of a previous survey.

Results: The percentage of women residents has increased to $84.6 \%$. A workload of more than 48 hours per week has resulted in decreased motivation and lower levels of satisfaction during training, although overall levels of satisfaction have clearly improved compared to the previous survey. Use of a logbook to create a more structured training program has not achieved the desired effect. Nevertheless, seven of eight gynecology residents would study medicine again, although $28 \%$ of the budding gynecologists are considering working abroad or in private industry.

Conclusion: Both training and overall satisfaction with working conditions must be improved to preserve the appeal of gynecology for young academics. This survey aims to identify key factors which are responsible for (dis)satisfaction with working conditions.

\section{Zusammenfassung \\ $\nabla$}

Einleitung: Im Jahr 2002 wurden die gynäkologischen Weiterbildungsassistenten in NordrheinWestfalen (NRW) erstmalig nach ihrer beruflichen Zufriedenheit befragt. Eine neue, erweiterte Umfrage unter den Weiterbildungsassistenten sollte klären, ob sich nach der Novellierung der Weiterbildungsordnung die Arbeitszufriedenheit verändert hat und in welchen Bereichen eine Verbesserung der Weiterbildungsbedingungen vordringlich ist.

Material und Methodik: Insgesamt 1223 Fragebögen mit jeweils 52 Fragen wurden an die 159 Frauenkliniken in NRW versandt. Die Antwortmöglichkeiten waren dichotom, mehrstufig oder quantitativ. Die Ergebnisse wurden auf Unterschiede hinsichtlich Alter, Geschlecht, Familienstand und Kliniktyp untersucht und zusätzlich mit den Ergebnissen der vorausgegangenen Umfrage verglichen.

Ergebnisse: Der Frauenanteil unter den Weiterbildungsassistenten ist auf $84,6 \%$ gestiegen. Bei einer hohen zeitlichen Arbeitsbelastung von über 48 Stunden pro Woche sinkt die Motivation und Zufriedenheit im Verlauf der Weiterbildung, auch wenn sich die Gesamtzufriedenheit im Vergleich zur vorangegangenen Umfrage deutlich verbessert hat. Das Logbuch als Anleitung für eine strukturierte Ausbildung erzielt nicht den erhofften Effekt. Trotzdem würden 7 von 8 Weiterbildungsassistenten wieder den Arztberuf ergreifen, auch wenn 28\% der angehenden Gynäkologen den Gang ins Ausland oder in die freie Wirtschaft erwägen.

Schlussfolgerung: Um die Attraktivität des Faches für den Nachwuchs zu erhalten, müssen sowohl die Weiterbildung als auch die allgemeine Arbeitszufriedenheit verbessert werden. Diese Umfrage versucht zentrale Faktoren aufzudecken, die für die Arbeits(un)zufriedenheit verantwortlich sind. 


\section{Introduction}

\section{$\nabla$}

Training and working conditions of physicians and medical residents are a matter of great public interest in Germany. As the specter of a future shortage of physicians looms and the general population ages, increasing numbers of young physicians are moving to work abroad or in other areas, aggravating the existing problem of a shortage of comprehensive medical care, particularly in rural areas [1]. The medical specialties gynecology and obstetrics are subject to the same demands and changes as other medical fields. As the number of women working in these fields has risen and the number of women working in gynecology and obstetrics is likely to increase even more, unsatisfactory working conditions which exacerbate the difficulty of combining family and career have an even greater negative impact [2]. Figures for 2012 obtained from the German Medical Association show that gynecology has by far the greatest percentage of women doctors (61.1\%), while other surgical specialties such as general surgery (19.7\%), otorhinolaryngology (33.7\%) and ophthalmology (45.3\%) have lower numbers of women and are therefore not as severely affected $[3,4]$. In 2002, the North Rhine-Westfalia Society for Gynecology and Obstetrics carried out its first survey into job satisfaction of medical residents in North Rhine-Westfalia (NRW). The survey found that $53 \%$ of young doctors were dissatisfied with their current work situation. The overwhelming majority $(88 \%)$ would have preferred a more structured training, which at the time was only available to $27 \%$ of medical residents [5]. The following year, in response to these demands and to improve training conditions, the German Society for Gynecology and Obstetrics and the German Professional Association of Gynecologists introduced the use of a model logbook. It was based on recommendations made by the European Board and College of Obstetrics and Gynaecology and aimed to complement the logbooks of the German Medical Association and the respective federal State Chambers of Physicians, which require that training is documented in accordance with specialist training regulations. Many clinics drew up new duty rosters for doctors in response to the much needed changes instigated by the German Working Hours Act. In 2004, NRW introduced new specialist training regulations with amended general working conditions. An extended survey of gynecology residents was done to determine the current mood and identify potential factors which contribute to job (dis)satisfaction. The results of this survey are presented here. This paper also discusses potential ways in which medical residents' aspirations can be reconciled with the reality of training.

\section{Material and Methods}

$\nabla$

Between February and May 2010, a total of 1223 questionnaires with 52 questions covering the topics "employment contract", "training", "working conditions", "satisfaction", "private life" and "health" were sent to medical residents of 159 gynecology clinics in NRW. The addresses of clinics authorized to offer residency training were obtained from the database of the respective Medical Associations for North Rhine and for Westfalia-Lippe. The chief physicians of all clinics were informed of the survey beforehand by telephone and were requested to supply the number of gynecology residents working at their clinic. Only seven of the listed clinics could not be reached or declined to participate. Responses to the questionnaire could be dichotomous, multi-level or quantitative, and were assessed using established measuring

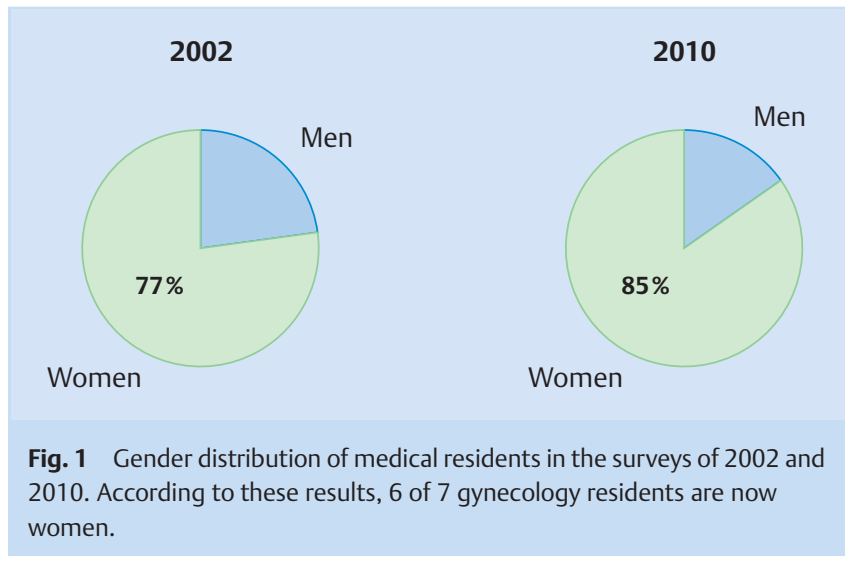

tools such as the smiley scale. Participation in a gynecology conference at a reduced rate was offered as an inducement to increase response rates. The responses were analyzed and subjects were classified into subgroups to investigate differences with regard to age, gender, family status and clinic type. Questions which had also been asked in the previous survey were additionally analyzed by comparing current responses with the results of the previous survey.

Statistical evaluation of questionnaires was done using Microsoft Excel and IBM SPSS Statistics version 19. Metric variables were compared using the two-tailed t-test, where possible. Differences in nominal or ordinal data were analyzed using the $\mathrm{X}^{2}$-test.

\section{Results \\ $\nabla$}

\section{General overview}

The final response rate from two thirds of all clinics which had previously received the questionnaire was $22.1 \%$ (270 returned questionnaires). The distribution of the response rate corresponded approximately to the distribution of medical residents in the respective clinic type $(26.4 \%$ in publicly funded clinics, $63.6 \%$ in denominational hospitals and $10 \%$ in privately owned hospitals). The response rate from clinics returning at least one questionnaire was $31.8 \%$, with university clinics slightly overrepresented at the expense of municipal hospitals. Only seven residents took up the proffered inducement to attend a gynecology conference at a reduced rate, indicating that this incentive failed in its desired effect. In 2002, $77 \%$ of gynecologists in training were women; in the current survey, the percentage of women gynecology residents had increased to $84.6 \%$ ( $\bullet$ Fig. 1 ). The chief physician of approximately every 10th department was a woman. On average, every clinic had 7.9 medical residents; the average number of beds per clinic was 56 and the average number of annual births per clinic was 1045 .

\section{Working conditions and workload}

The contractual working hours for persons on full-time contracts are 43.1 hours per week; however, on average, every medical resident worked an additional 5.3 hours overtime per week. The weekly hours of work depended on the type of clinic. Gynecology residents working in private hospitals worked 46.2 hours per week while the average weekly working hours of residents working in university clinics were 60.3 hours and thus significantly longer $(p<0.01)$. There were also considerable differences with 


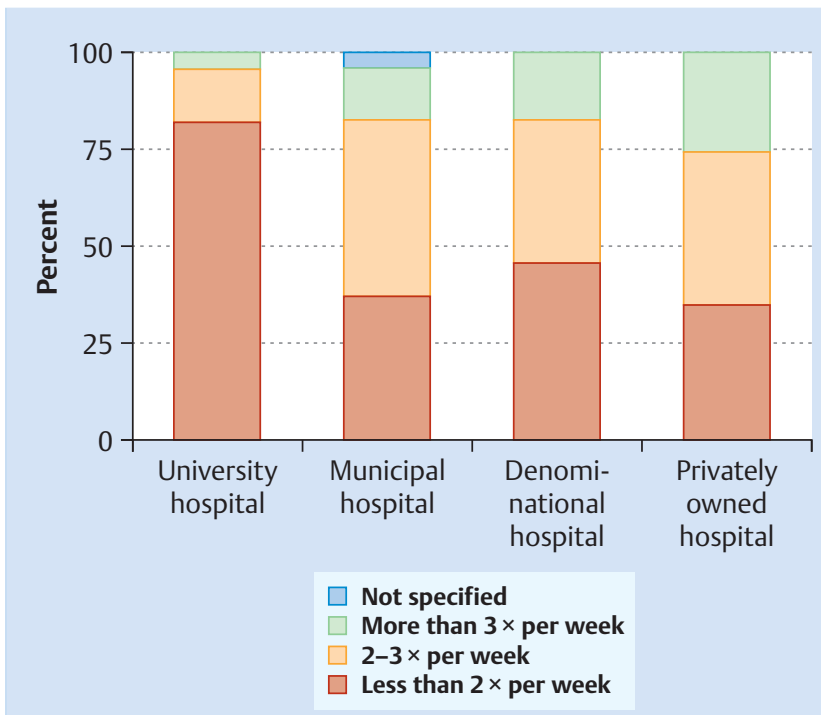

Fig. 2 Percentage of residents able to take their statutory daily break of 30 or 45 minutes. Significantly fewer residents in university clinics were able to take their statutory daily break compared to other types of hospitals.

regard to compensatory time-off or payment for accrued overtime. $17.5 \%$ of medical residents working in denominational hospitals reported that they received no form of compensation, while the same figure for residents working in municipal hospitals was $32.6 \%$. Men were twice as likely to criticize the lack of compensation compared to their female colleagues. The number of residents who were able to take their daily statutory rest periods as prescribed in the German Working Hours Act also differed greatly, depending on the type of hospital. $34.8 \%$ of medical residents working in private hospitals were able to take the statutory break only once a week; in university hospitals, $81.8 \%$ of medical residents could take the statutory break only once a week, at best ( Fig. 2). On average, the young gynecologists felt overwhelmed with work 2 days in every week, although the work atmosphere was only described as poor for 1 of every 15 departments. $46 \%$ of residents reported decreased motivation and lower levels of job satisfaction. Almost the same number of residents had looked for job vacancies in other hospitals over the last 3 months.

Logbook used in own training

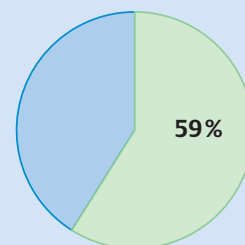

Fig. 3 Prevalence and use of logbooks in training. Introduction of the logbook did not necessarily lead to improvements in medical training.

\section{Assessment of training}

After the logbook was introduced, the percentage of jobs offering structured training increased from 27 to $59.2 \%$. But the majority of medical residents have not derived any benefit in terms of training: overall, only $24.1 \%$ of gynecologists in training in NRW benefitted from the introduction of the logbook 10 years ago ( Fig. 3). Asked whether the catalogue of work experience and training required prior to obtaining approval as a medical specialist in gynecology and obstetrics was realistic, $44 \%$ of residents in 2002 considered the extent of training listed in the catalogue as appropriate or even as too low. In the current survey, this figure had increased to $74.5 \%$ ( Fig. 4). However, 30\% of residents suspected that documentation of work experiences in their department was inflated to fulfil the necessary conditions for approval as a medical specialist. The figure was significantly higher for residents at university hospitals and amounted to 50\% $(p<0.05)$. On average, one hour of in-house training per week was given, but $97 \%$ of residents considered it to be important to attend external training courses to comply with regulations on specialist training and obtain additional qualifications.

\section{Job satisfaction of medical residents}

Evaluation of residents' satisfaction with working conditions and overall satisfaction showed that 44 and $45 \%$, respectively, were satisfied or very satisfied. The number of dissatisfied or strongly dissatisfied residents in both areas were significantly lower with 17 and $20 \%$, respectively ( Fig. 5). Seven of eight respondents would study medicine again, if given the choice. Asked about their future career plans, $96 \%$ replied that they intended to pursue a typical career in medicine (hospital or medical practice). As multiple answers to this question were allowed, $28 \%$ of the residents also considered working in private industry or abroad (๑ Fig. 6).

\section{Impact on their private life}

$88 \%$ of medical residents were in a long-standing relationship and $23 \%$ had children. $82 \%$ of the residents criticized the restrictions their job placed on their private life. More than three quarters of all residents reported that they were regularly too tired after finishing their work to do something with their partner, their children or their friends.

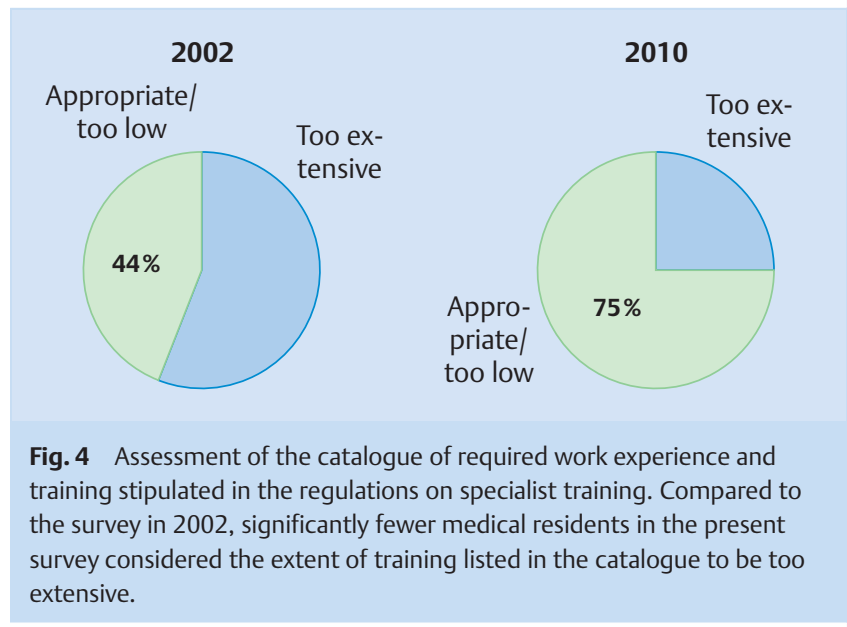




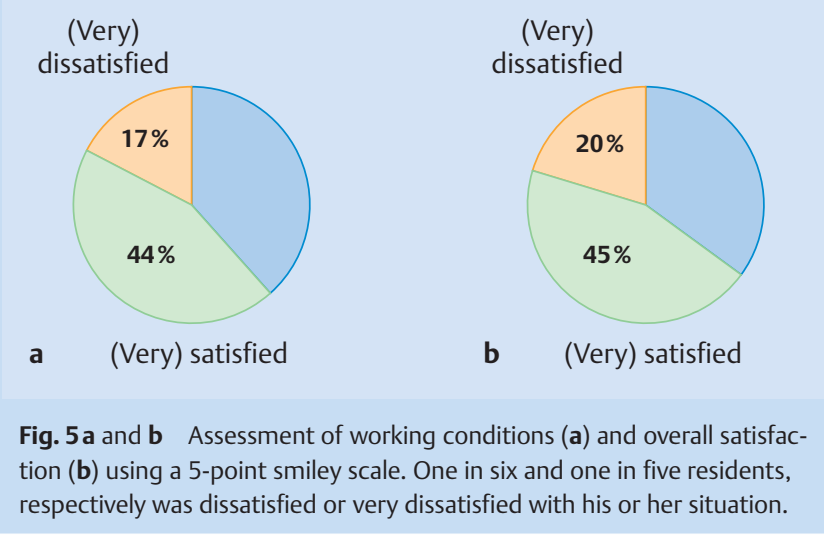

\section{Alarming health behavior}

The average number of days absent from work due to illness was 3.7 days per year, which is much lower than the average for the general population of 17.3 days and also lower than the average for doctors in general, which is 7.0 days annually [6]. The medical residents working in university hospitals deviated even more significantly from the norm, calling in sick on average only 2.3 days per year $(p<0.05)$. Significantly more medical residents working part-time did not report a needlestick injury to their professional association compared to full-time employees $(p<0.05)$. A total of $61.9 \%$ of respondents answered the question whether they had ever taken medication at work to be able to continue working in the affirmative; there were no statistical differences between
Hospital or medical practice (multiple answers possible)

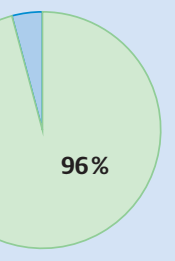

Abroad/private industry (multiple answers possible)

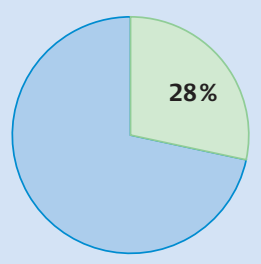

Fig. 6 Career plans of trainee specialist physicians. The majority of residents planned to pursue a typical career in medicine, but many did not rule out a change of career.

subgroups. Asked whether they had experienced any personal discrimination at work due to pregnancy, $32.6 \%$ of doctors who had been, or currently were, pregnant acknowledged that this had been the case. Here too, there were no statistically significant differences between subgroups. The frequency in which medical residents participated in sporting activities was also evaluated. According to our survey, more than one third (36.3\%) did no sports whatsoever. Significant risk factors for physical inactivity included working part-time $(\mathrm{p}<0.05)$, children $(\mathrm{p}<0.01)$ and marriage or being in a long-standing relationship $(p<0.01$; O Fig. 7).
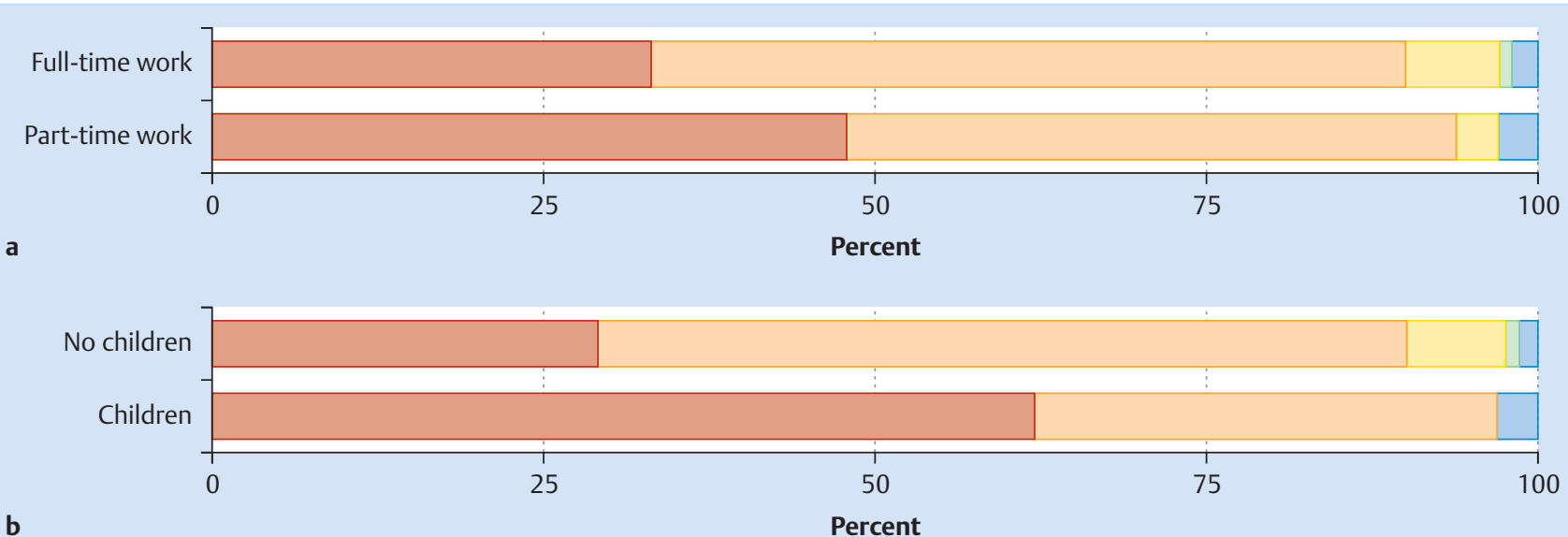

b

Percent

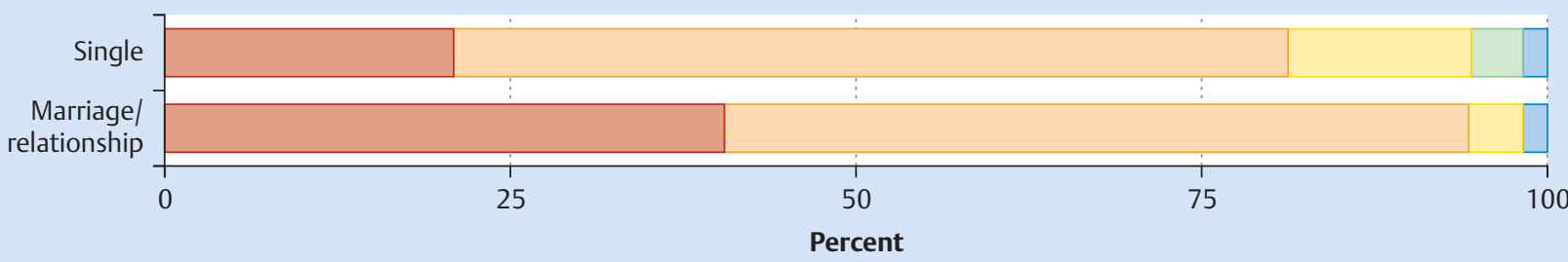

$\square$ Never $\square$ 1-2 $\square$ 3-4 $\square$ More than $4 \quad \square$ Not specified

Fig. 7 a to $\mathbf{c}$ Risk factors for physical inactivity. There were significant differences between subgroups with regard to regular sports activities (at least 1 hour of sports on $\mathrm{x}$ days per week): a full-time work vs. part-time work $(p<0.05)$; b no children vs. children $(p<0.01)$; $\boldsymbol{c}$ single vs. marriage/relationship $(p<0.01)$. 


\section{Discussion}

\section{$\nabla$}

Given the large numbers of surveys of doctors, particularly surveys investigating job satisfaction, it can be difficult to make participants understand the necessity of carrying out yet another survey. In the survey presented here, despite the inducement of a reduced fee to attend a medical conference and prior notification of every department by telephone, only $22.1 \%$ of residents and their heads of departments could be persuaded of the importance of this survey. This may be due on the one hand to a certain satiation effect, on the other hand to the high workloads of doctors and the extensive documentation they are already required to complete as part of their work. But surveys like this are indispensable because they allow us to assess the current situation and future needs of young medical professionals. This survey has certain limitations which need to be taken into account when considering the results. These limitations include the limited response rate and the fact that it was not possible to poll the same persons who participated in the 2002 survey. Both gender distribution and clinic type were representative, as the information provided by the respondents largely corresponded to the figures obtained from the German Medical Association and the German Federal Statistical Office [3,7]. The knowledge obtained from this survey largely supports what was previously known about current problems as demonstrated by the two evaluations of medical residency carried out to date by the German Medical Association. One caveat raised was that the training required for specific medical specialties cannot be done only during regular working hours. The on-call duty rosters only complied with the statutory regulations of Working Hours Act in $20.4 \%$ of cases, a much lower figure than the average for all medical specialties. More than half of all overtime is not fully compensated $[8,9]$. This survey also showed that past attempts at implementing changes did not always result in changes to actual working conditions of medical residents and, in some cases, faced obstruction. According to current estimates, there will be a shortage of approximately 37000 doctors in German hospitals by 2019 [10]. At the same time, around $40 \%$ of persons currently studying medicine are considering working in non-medical areas [11]. The situation has been additionally exacerbated in gynecology because changes to duty rosters have meant that trainee doctors are required to spend fewer hours in hospital, greater numbers of doctors are required on duty, and demands with regard to the qualifications of the doctors on duty have increased, particularly in the field of obstetrics [12].

To ensure that gynecology remains attractive to trainee doctors and to prevent gynecologists from moving to work in other, non-medical fields or abroad, training and general levels of job satisfaction must urgently be improved. Improving levels of job satisfaction largely depends on the work being perceived as positive and meaningful, on good relationships between doctors and patients, and on a pleasant atmosphere at work [13]. To provide in-depth training we would propose the creation of comprehensive in-house mentoring programs in addition to the consistent and honest use of logbooks. In addition, although it is obviously necessary to document procedures and activities, the amount of time spent on administrative duties is currently estimated by medical residents to be around $50 \%$ and should be reduced. Even though levels of job satisfaction have apparently increased, the workload of residents must be decreased. The average hours worked by medical residents per week are already higher than the statutory limit of 48 hours (EU Directive 2003/88/EC), although these hours have not been systematically recorded [14]. But providing specialist training must also be economically viable for hospitals to ensure that hospitals have a long-term interest in providing structured training for medical residents and are not merely complying with social expectations. The lower salaries of medical residents only partly compensate for the additional time spent by their instructors and the longer operating times. This is an area where the Central Federal Association of Healthcare Insurance Funds need to step in to create suitable incentives by amending the compensation rates to reflect the evaluated quality of the training provided in hospitals [15].

The questions about the number of residents who took their statutory breaks or who were prepared to take medication to be able to continue working showed that routine working conditions for doctors in hospitals urgently need to be improved, also in the interests of patient care. At least clinic directors have recognized that the pace of work demanded of medical residents and the time pressures this creates are very high [16]. In addition to strict compliance with statutory regulations on maximum working hours, information campaigns could raise the awareness of doctors and allow them to detect signs of overwork early on, as studies have reported that every seventh doctor has higher levels of two thirds of the stress indicators used when screening for burnout syndrome than the average levels recorded for depressive patients [17]. An analysis of personnel costs at the University Gynecological Clinic of Tübingen showed that the necessary amendments to roster schedules will not inevitably place greater financial burdens on clinics [18]. Regularly giving a share of the revenue generated by treating private patients in hospital to medical residents should be a matter of course. This form of acknowledging their services could also be a means of guarding against "gratification crises", the term used by J. Siegrist to describe the imbalance between personal input and the lack of recompense for this dedication [19]. It will also be necessary to take account of the increasing "feminization" of medicine, and of gynecology in particular, because the issue of reconciling work and family responsibilities will become increasingly important. According to a survey by the German Society for Gynecology and Obstetrics, only $10 \%$ of women respondents currently aspire to a senior position as a senior consultant for gynecology. Given the current high percentage of women residents, this will result in a serious shortage of senior consultants in the foreseeable future. Increasing the availability of childcare, offering initial support to new consultants and permitting job-sharing of consultant positions will be necessary to encourage women to pursue a career in gynecology [20]. Implementing flexible work roster schedules and expanding in-house daycare facilities would be additional steps which would make it easier for young doctors to combine family responsibilities and a career. New legislation to ensure the widespread availability of childcare outside hospitals and the expansion of state benefits (e.g. parental allowances) would encourage doctors in a relationship to choose ways of sharing family responsibilities while pursuing a career which do not mirror the traditional division of labor [21]. This would also take the wishes of many young mothers and fathers into account who wish to share the responsibilities of family and career equally. 


\section{Conclusion}

$\nabla$

Our field of medicine must be made more attractive to the increasing numbers of young female academics. To ensure that gynecology and obstetrics are an attractive career option it will be necessary to offer more structured teaching and improve general levels of job satisfaction. This can be done through a consistent and objectively verifiable use of logbooks, the introduction of mentoring programs in hospitals, the reduction of administrative duties, and the improvement of general working conditions, with non-medical tasks shifted to other, non-medical staff. In particular, the wish to combine family life and career with the pregnancies and periods of parental leave this entails must not result in discrimination. Only employers and supervisors who are prepared to show consideration and accommodate this natural desire for a family will be able to retain important employees and colleagues in future.

\section{Note}

$\nabla$

The results of this survey of resident gynecologists in NRW published here were taken from the Author's master's thesis in Public Health.

\section{Conflict of Interest}

$\nabla$

None.

\section{References}

1 Richter-Kuhlmann E. Die Lücken werden größer. Dtsch Arztebl 2010; 36: $1670-1671$

2 Riepen $V$, Möbus $V$, Kullmer $U$ et al. Male and female physicians in hospital gynaecology departments - analysis of the impact of "feminisation" from the viewpoint of medical directors. Geburtsh Frauenheilk 2013; 73: 53-58

3 Bundesärztekammer. Ärztestatistik 2012. Online: www.baek.de

4 Fuss I, Nübling M, Hasselhorn HM et al. Working conditions and workfamily conflict in German hospital physicians: psychosocial and organisational predictors and consequences. BMC Public Health 2008; 8: 353

5 Schmutzler RK, Jung $V$. Was erwarten die Weiterzubildenden von der neuen Weiterbildungsordnung? Frauenarzt 2002; 43: 777-781
6 WIdO. Fehlzeiten-Report. Pressemitteilung des Wissenschaftlichen Instituts der AOK. Berlin: Springer; 2012: 291-340

7 Statistisches Bundesamt. Grunddaten der Krankenhäuser. Fachserie 12. Gesundheitswesen. Wiesbaden: Statistisches Bundesamt; 2009: 3645

8 Bundesärztekammer. Ergebnisse der Evaluation der Weiterbildung. 1. Bundesrapport 2010; 24-53

9 Bundesärztekammer. Ergebnisse der zweiten Befragung 2011. Evaluation der Weiterbildung: Frauenheilkunde und Geburtshilfe; 2011: 1-34

10 Blum K, Löffert S. Ärztemangel im Krankenhaus - Ausmaß, Ursachen, Gegenmaßnahmen. Düsseldorf: Deutsches Krankenhausinstitut e.V.; 2010: 25-38

11 Dettmer S, Kuhlmey A, Scholz S. Gehen oder bleiben? Dtsch Arztebl 2010; 107: B25-B27

12 Beckmann $M W$, Bader W, Bechtold I et al. Financing and financial problems of care and structures in the field of gynaecology and obstetrics in the year 2011 - DRG system and inpatient care with urogynaecology and benign and malign gynaecological surgery. Second paper of the financing commission of the DGGG e.V. - Part II. Geburtsh Frauenheilk 2011; 71: 497-510

13 Bussche $H$. Arbeitsbelastung und Berufszufriedenheit bei niedergelassenen Ärztinnen und Ärzten: Genug Zeit für die Patientenversorgung? Report Versorgungsforschung 2010; 235-242

14 IQME. Ergebnisbericht der Mitgliederbefragung. Marburger Bund Monitor 2013; 9

15 Beckmann MW, Bader W, Bechtold I et al. Financing and financial problems of care and structures in the field of gynaecology and obstetrics in the year 2011 - general aspects and obstetric care. Second paper of the financing commission of the DGGG e.V. - Part I. Geburtsh Frauenheilk 2011; 71: 367-380

16 Pfaff H, Ernstmann N, Ommen O et al. Die Sicht ärztlicher Direktoren. Deutsches Ärzteblatt 2010; 107: B-656-B-657

17 Geuenich $K$. Sind Sie burnout-gefährdet? Ergebnisse einer empirischen Ärztestudie. Der Hausarzt 2009; 20: 2-4

18 Maschmann J, Holderried M, Blumenstock $G$ et al. Impact of new shift models for doctors working at a German university hospital for gynaecology and obstetrics four years after implementation. Can they meet the European Working Time Directive without increasing costs? Geburtsh Frauenheilk 2013; 73: 713-719

19 Siegrist J. Soziale Krisen und Gesundheit. Eine Theorie zur Gesundheitsförderung am Beispiel von Herz-Kreislauf-Risiken im Erwerbsleben. Göttingen: Hogrefe-Verlag; 1996

20 Ramsauer B, Rhiem K. Warum es Männer nicht mehr gibt und Frauen nicht wollen. Kommission Familie und Karriere der DGGG, 58. Kongress der DGGG 2010

21 Henne-Bruns D. Academic career in medicine: how to combine work and family - why are there so few female doctors in Germany in senior positions? Geburtsh Frauenheilk 2009; 69: 922-924 